\title{
5 Parasitic Plants
}

Parasitic plants form a close connection with the vascular system of their host plant(s) through a specialised structure known as a haustorium (plural haustoria), that physically connects the parasite to the host, providing a vascular conduit for water and nutrients (and sometimes sugars and amino acids) from host to parasite. They are dependent on their host for their supply of mineral/inorganic nutrients, water and/or organic compounds, although the degree of host dependency varies greatly between species. Almost $1 \%$ of the world's flowering plants are parasitic ( $\sim 3,000$ species), and it is estimated that parasitism has appeared at least 11 times during the evolution of angiosperms (Barkman et al., 2007).

A hemiparasite [half parasite] obtains water and mineral nutrients from the host xylem but is also photosynthetic. Some hemiparasites also obtain limited amounts of carbohydrates from the host phloem. The haustoria are either attached to the host's shoot or root. Holoparasite [whole parasite] is where the parasite is non-photosynthetic and obtains water and nutrients from the host xylem and carbohydrates from the host phloem. The parasite occurs within the host's shoot or root tissues. Holoparasites are less common than hemiparasites in the SouthWest flora (Table 5.1).

Table 5.1: Parasitic genera in southwestern Australia. Root = root parasite, shoot = shoot parasite. Data obtained from Florabase (florabase.dpaw.wa.gov.au), accessed October 2013.

\section{Loranthaceae (hemiparasites) Amyema (12 species; shoot) Lysiana (2 species; shoot) Nuytsia (1 species; root)}

Santalaceae (hemiparasites) Santalum (4 species; root) Anthobolus (1 species; root) Choretrum (3 species; root) Exocarpos (3 species; root) Korthalsella (1 species; shoot) Leptomeria (12 species; root) Spirogardnera (1 species; root)

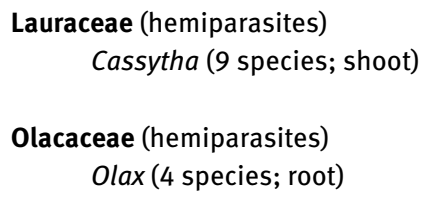

\subsection{Stem Hemiparasites - Mistletoes}

Worldwide, only three of the 75 genera in the family Loranthaceae do not display the typical 'mistletoe' habit, i.e. clumps of foliage attached to host branches (Wilson \& Calvin, 2006). One of these is the WA christmas tree (Nuytsia floribunda). Two aerial 
mistletoe genera occur within the SouthWest flora-Amyema and Lysiana (Fig. 5.1), of which $80 \%$ of the species are endemic. Korthalsella arthroclada (Santalaceae) also displays the mistletoe habit, and only parasitises Melaleuca lanceolata beside salt lakes near Eneabba.

Mistletoes have no root system, and germinate without the need for free water. They parasitize trees and tall shrubs and may be host specific. The seeds are surrounded by a sticky mucilage that enables them to adhere to a host branch. If deposited on a dead branch, the mistletoe is free-living for five months before it starts to die, and unable to survive on non-host living branches for more than 6 months (Yan, 1993b). Although mistletoes possess green foliage and thus produce their own carbohydrates, they are entirely dependent on their host for their water and inorganic nutrient supply. Mistletoes have higher transpiration rates than their host plants. Higher transpiration rates are essential to 'pull' water from the host plant. They also possess higher concentrations of inorganic nutrients, especially potassium and (uniquely in the SouthWest) sodium that also increases the osmotic concentration on the mistletoe side of the union.

\subsubsection{Host Mimicry}

Because mistletoes have high levels of nutrients (especially potassium, sodium, nitrogen, phosphorus) in their leaves (Lamont, 1983), they are relatively nutritious (compared with their hosts) and are an easy target for herbivores. Many mistletoes have developed leaves that mimic the foliage of the host plant (Fig. 5.1). Some are restricted to a few species or predominately parasitize a particular genus (Yan, 1990) (e.g. Amyema preissii on Acacia; Amyema melaleucae on Melaleuca), others have many hosts (e.g. Amyema miquelii has 125 host species). Host specificity is a function of bark and xylem resistance to haustorial penetration (Yan, 1993c).

There are many tree and tall-shrub species that are not susceptible to mistletoe parasitism (see Table 5.2 for a list of mistletoe hosts). Of the $\sim 25,000$ vascular plants in Australia 870 are known to serve as host species (Downey, 1998).

Amyema is a xylem-tapping genus (Fig. 5.1) with no known ability to abstract phloem-borne solutes from its hosts. Mistletoes establish xylem-xylem contact early in the development of the endophyte, although direct xylem contacts are relatively few due to the large numbers of parenchymatous (non-specialised) cells at the interface. They derive no organic nutritional benefit apart from small amounts of carbon compounds in the transpiration stream. 

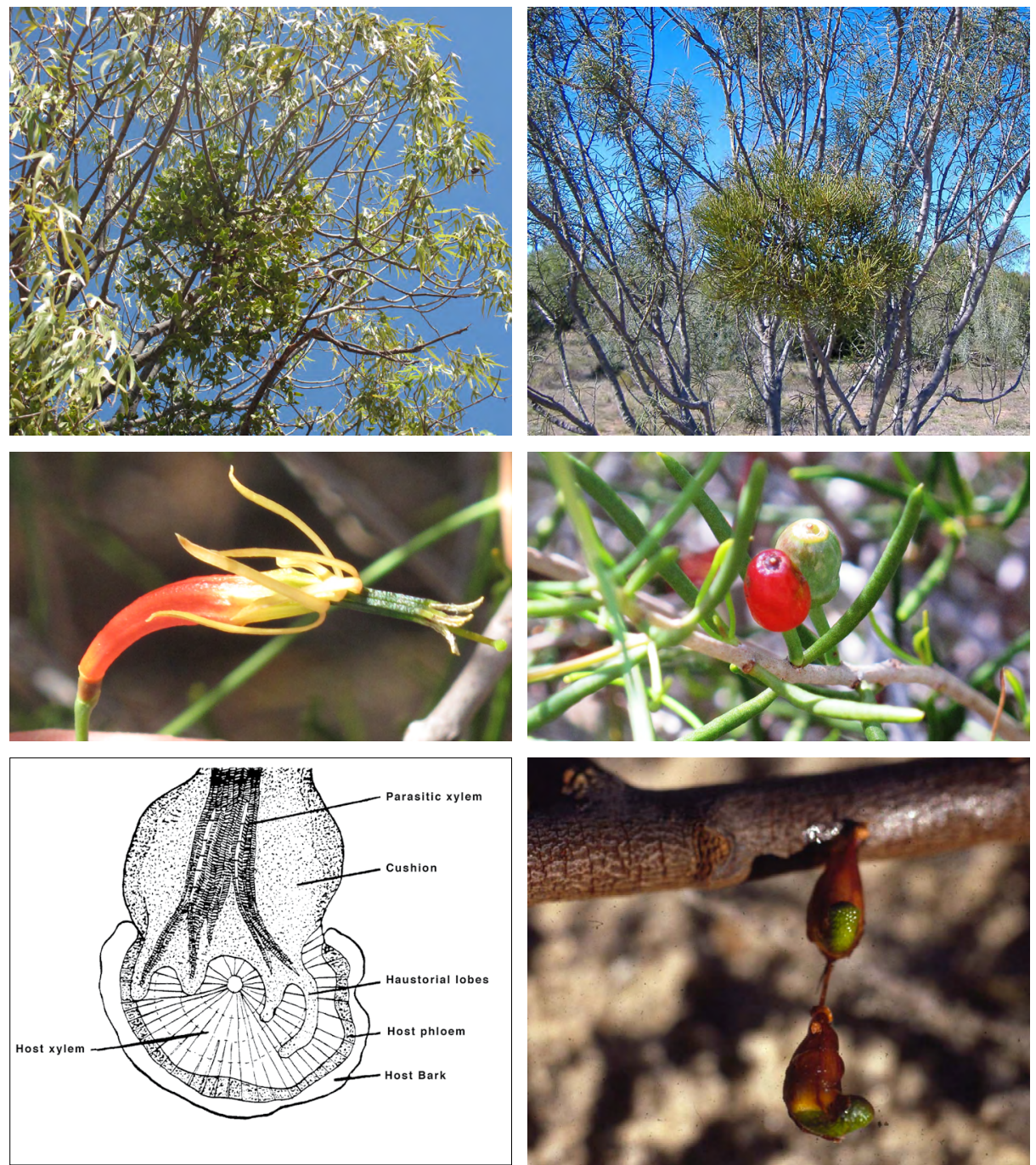

Fig. 5.1: (upper left) Amyema benthamii (centre) hosting on Brachychiton gregorii (Malvaceae). (upper right) Amyema gibberula (centre) on Hakea recurva (Proteaceae). Note that both species show host mimicry in their foliage. (middle) Flower ( $2.5 \mathrm{~cm}$ long) and fruit ( $8 \mathrm{~mm}$ long) of the mistletoe Lysiana casuarinae (Loranthaceae). As the flower opens the petals fold back to reveal the long green stamens. The fruit (a berry) ripens to a red or black colour. L. casuarinae has long (up to $9 \mathrm{~cm}$ ) needle-like leaves, and in this case was hosting on Acacia acuminata (Fabaceae). (lower left) Drawing of a cross section through a young Amyema haustorium and the infected stem of a host. Host stem diameter is $3 \mathrm{~cm}$. (lower right). Two Amyema seeds ( $6 \mathrm{~mm}$ long) deposited simultaneously by a mistletoe bird, though only one is attached to the host branch. The green haustorium is visible on each seed, growing towards the branch (negative geotropism). 
Table 5.2: List of southwestern Australian Amyema and Lysiana species. Based on information obtained from the WA Herbarium online database, Florabase, accessed October 2013. Examples of SouthWest hosts and number of host species obtained from Downey (1998).

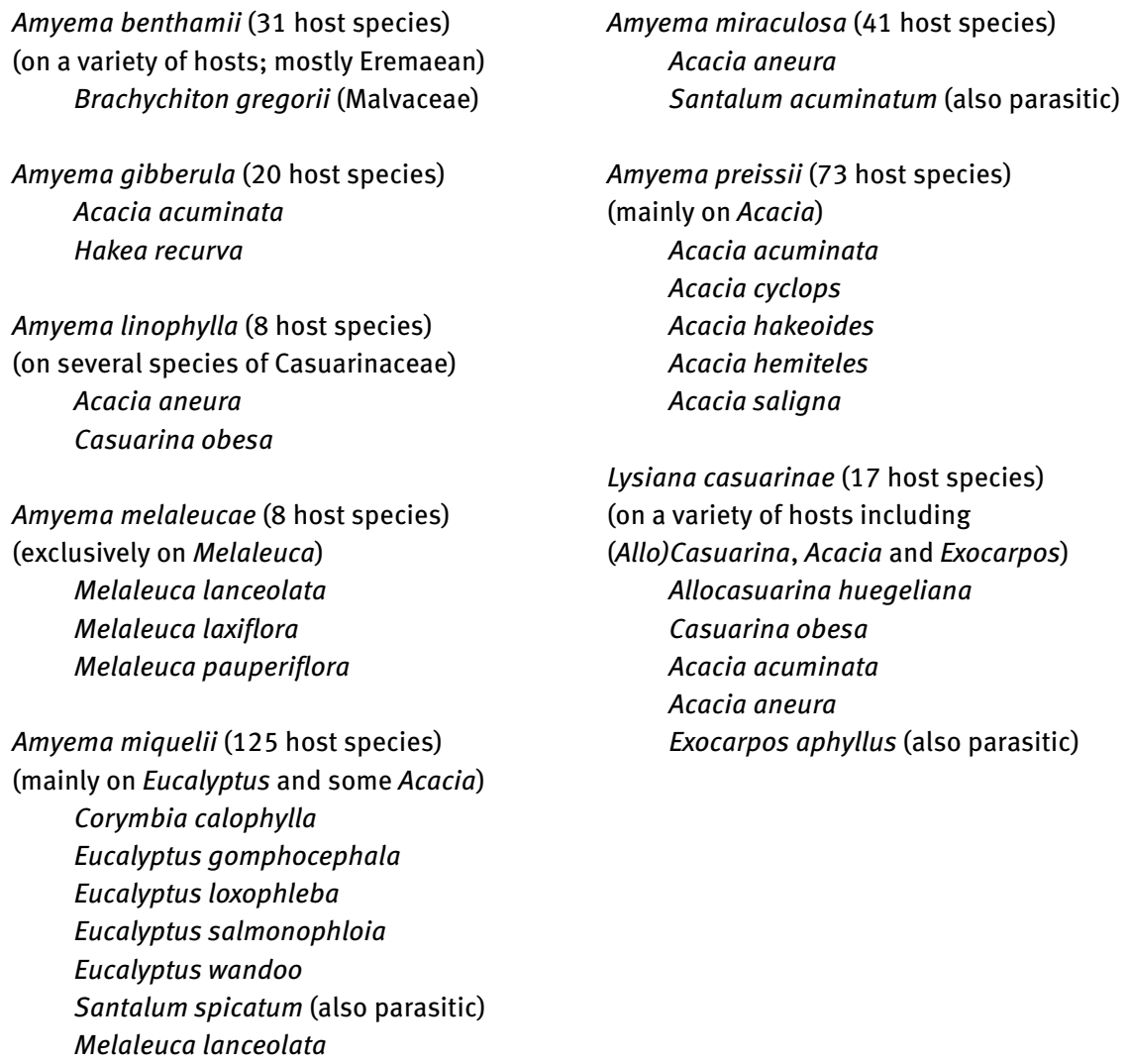

\subsubsection{Seed Dispersal}

Amyema and Lysiana fruits are a succulent berry (Fig. 5.1) that is attractive to birds, including the Australian mistletoe bird (Dicaeum hirundinaceum: Dicaeidae) (Yan, 1993a). The conspicuous berry is swallowed whole (minus the outer rind) and many berries can be consumed in one feeding session.

The mistletoe bird defecates the sticky seeds onto a host branch (Fig. 5.1). Because the seeds are surrounded by a sticky mucilage layer, the bird has developed a special 'bottom-wiggle' or 'zig-zag' dance to wipe off the voided seed clinging to its cloaca, which ensures that seeds are deposited onto a branch. The mistletoe bird has an extremely short intestinal system, and seeds are defecated 30 minutes after being 
consumed. This explains why mistletoes tend to be crowded on and around a given host plant.

Once Amyema seeds have matured, they remain dormant in the berry (Fig. 5.2). Excision from the berry is the main trigger to promote germination and growth, which may commence within 10 hours of the excision event occurring (i.e. removal by the mistletoe bird) (Lamont, 1983). The high carbon dioxide $\left(\mathrm{CO}_{2}\right)$ concentration that occurs within the berry is sufficient to maintain dormancy while the seed remains within the berry (Lamont, 1982).

The outer rind of the berry is impervious to gas movement in or out of the berry, but allows $40 \%$ of photosynthetically active radiation (light at $400-700 \mathrm{~nm}$ wavelengths) to pass through that is used by the chlorophyll-bearing embryo to undergo limited photosynthesis during the day (Lamont \& Perry, 1977). However, respiration occurs both night and day so $\mathrm{CO}_{2}$ production exceeds oxygen $\left(\mathrm{O}_{2}\right)$ production overall, preventing further growth of the embryo.

This causes a buildup of $\mathrm{CO}_{2}$ in the berry at concentrations greater than that in the earth's atmosphere. When the seed is excised (i.e. via the dispersal process involving the mistletoe bird), it becomes exposed to low $\mathrm{CO}_{2}$ and high $\mathrm{O}_{2}$ concentrations and can germinate. Light is also important in assisting Amyema germination, as the sugars produced via photosynthesis are required to support tissue growth (Lamont \& Perry, 1977). It must rely on its own store of water and nutrients until the young haustorium penetrates the host bark and reaches its xylem.

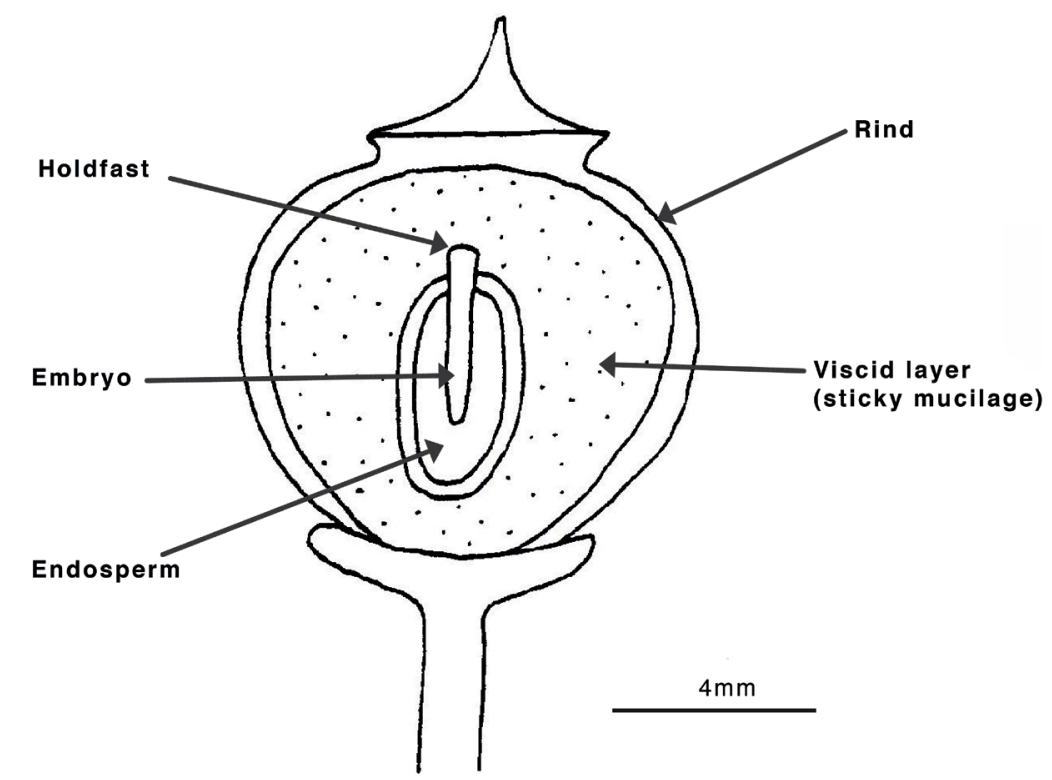

Fig. 5.2: Diagram of a longitudinal section through a mature Amyema berry. 


\subsection{Root Hemiparasites}

\subsubsection{Nuytsia Floribunda (Loranthaceae)}

Nuytsia floribunda is the only species in its genus and its biology is so distinctive it was once considered to be a monotypic family (Hopper 2010). The species epithet, floribunda, meaning 'lots of flowers', refers to the spectacular display of orange flowers that occurs annually between November to January (Fig. 2.4), and hence is known locally as the Western Australian christmas tree. Nuytsia is a tree mistletoe that parasitizes a range of plant species (Calladine \& Pate, 2000), and is ancestral within the Loranthaceae: it originated $45 \mathrm{Ma}$ and is a true relict of the Eocene Epoch (Wilson \& Calvin, 2006; Vidal-Russell \& Nickrent, 2008a; b).

The fruits are three-winged and wind dispersed (Fig. 5.3) that is unique within the order Santalales. The papery wings also have an important function in absorbing and channelling rainwater to the germinating seed. However, regeneration is mostly in the form of stem suckers arising from long underground rhizomes. These stem suckers develop a shallow root system that ultimately bears the fine haustoria-producing rootlets that attach to, and sever, the host roots (Fig. 5.3). Seedlings can survive and grow without a host for up to 4 years, provided there are sufficient nutrients available in the soil.

Nuytsia produces numerous ring-like haustoria (called haustoriogens) that surround the host root. They have even been known to attach to underground telephone cables and trickle irrigation pipes (Fig. 5.3). Once the host root has been surrounded, a cutting device develops (Fig. 5.3) that commences to penetrate the root (Calladine \& Pate, 2000). This cutting device is pushed through the host root by hydrostatic forces, and eventually becomes lodged in haustorial tissue on the opposite side of the host root. Endophytic tissue develops from the haustoriogen to each end of the host's cut xylem. There is no phloem in the haustorial endophyte, only paired xylem strands. 

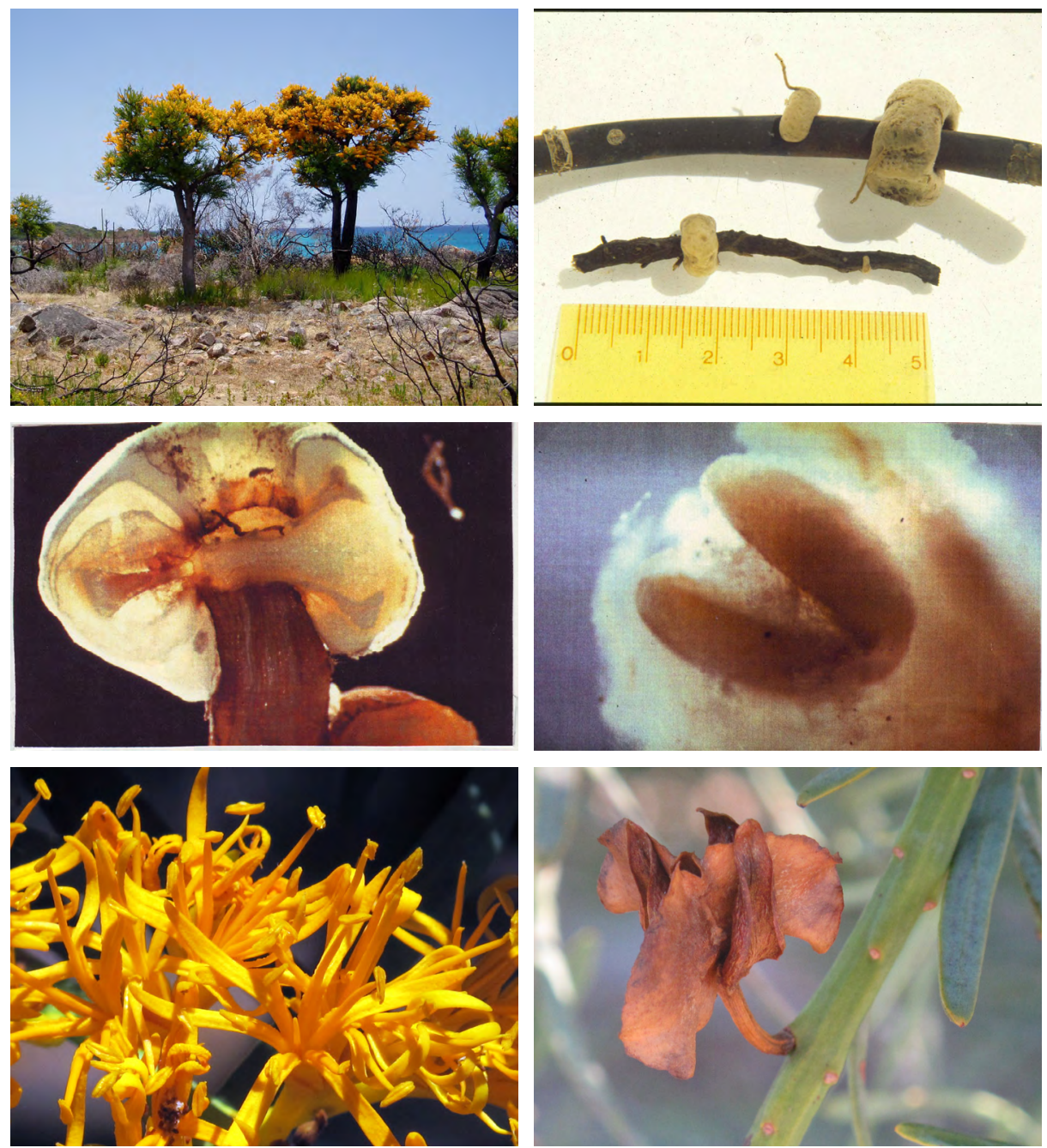

Fig. 5.3: (upper left)) Nuytsia floribunda growing on granite. Plants are $3 \mathrm{~m}$ tall, with the three visible stems arising from the same parent rhizome. (upper right) Nuytsia haustoriogens attached to an underground telephone cable (top) and Banksia host root (lower). Haustoriogens range from 5 to $10 \mathrm{~mm}$ in diameter. (middle left) Section through a haustoriogen that has severed a host root. The cutting device is pushed through the host root via hydrostatic pressure and in this photo is lodged in the left-hand side of the endophytic tissue. (middle right) The sharp sclerenchymatous horn (cutting device) that slices through the host root like a pair of shears, $4 \mathrm{~mm}$ long. (lower left) Nuytsia flowers occur in triads. From the single bisexual flower a winged fruit develops (lower right) held in place by three woody bracts, $15 \mathrm{~mm}$ long. 


\subsubsection{Olax phyllanthi (Olacaceae)}

Olax is a root hemiparasite, with 5 species recorded as occurring in the SouthWest flora. The name Olax is derived from the Latin for "evil smelling" and refers to the unpleasant smell of some Asian species. phyllanthi relates to the pale soft leaves, that look similar to those of Phyllanthus (Euphorbiaceae).

O. phyllanthi is a shrubby species that establishes multiple haustorial contacts with roots of a wide range of woody and herbaceous host species (Pate et al., 1990a; b). Acacia littorea on coastal dunes is a favoured natural host (Tennakoon et al., 1997). Haustoria penetrate laterally to the host xylem where a predominately parenchymatous interface absorbs water, minerals and organic solutes from the host (Pate et al., 1990a). Olax roots rarely reach below a depth of $30 \mathrm{~cm}$, thus attachment to deep-rooted host species is essential for their summer survival. Haustorial contacts only form in autumn-spring and are made on both perennial and herbaceous species (Pate et al., 1990b).

Damage to hosts is minimal and secondary thickening (of the host) continues on the side of a host root opposite to a haustorium. The developing sucker spreads laterally around the surface of the host xylem (Pate et al., 1990b), but never completely encircles the host stele, unlike Nuytsia.

\subsubsection{Santalum (Santalaceae)}

Four species of Santalum occur in the SouthWest. The name is derived from the Greek santalon, meaning sandalwood (specifically referring to the Indian sandalwood). S. acuminatum (quandong) and S. spicatum (sandalwood) parasitize multiple woody host species, especially legumes such as Acacia acuminata.

Santalum has a 'bell-shaped' haustorium that partially encircles the host root (Fig. 5.4) and is extremely efficient at metabolising some of the amino acid (nitrogen-based) compounds transported in the host's transpiration stream. Like other hemiparasites, Santalum transpires more than its hosts (Tennakoon et al., 1997; Loveys et al., 2001). 

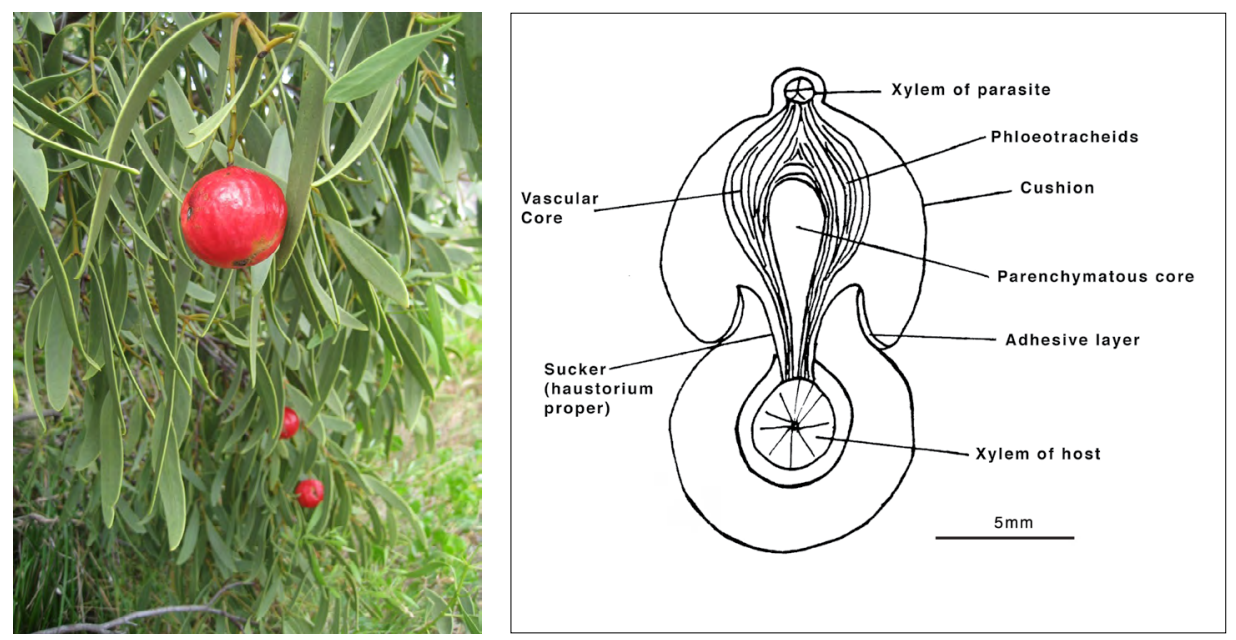

Fig. 5.4: (left) Leaves and fruits ( $3 \mathrm{~cm}$ in diameter) of Santalum acuminatum (quandong). (right) Drawing of longitudinal section through a Santalum haustorium attached to a host root.

\subsection{Stem Holoparasites}

\subsubsection{Pilostyles (Apodanthaceae)}

Pilostyles parasitizes only pea-flowered legume genera (Dell \& Burbidge, 1981; Table 5.3). Pilostyles traditionally was positioned within the family Rafflesiaceae, which includes the holoparasitic, large-flowered Rafflesia (confined to southeast Asia), but is now considered a member of the related Apodanthaceae. Pilostyles species are small-flowered, with the name derived from the Greek words pilos (= hat) and stylos (= pillar) and refers to the shape of the style.

Table 5.3: Diagnostic features of the three SouthWest Pilostyles species (from Thiele et al., 2008).

\begin{tabular}{|c|c|c|c|}
\hline & P. hamiltonii & P. coccoidea & P. collina \\
\hline Distribution & Eneabba to Bunbury & Eneabba to Moore River & Stirling Range, Hyden, Peak Charles \\
\hline Host genus & Daviesia & Jacksonia & Gastrolobium \\
\hline Sexual strategy & Dioecious & Monoecious & Monoecious \\
\hline Host position & $\begin{array}{l}\text { on young stems } \\
\text { (<2 year-old) }\end{array}$ & $\begin{array}{l}\text { Usually on old wood; } \\
\text { sometimes on young } \\
\text { stems }\end{array}$ & On young stems \\
\hline
\end{tabular}


Legumes have the capacity, via a symbiotic association with nitrogen-fixing bacteria, to metabolise atmospheric nitrogen occurring in soil air pockets (see Chapter 6). Pilostyles targets legume species because legume tissues typically have a high nitrogen concentration. There are three Pilostyles species in the SW flora (Table 5.3). The plant body of Pilostyles is greatly reduced, and until it flowers, exists solely as a series of cellular strands within the secondary phloem of the host.

Pilostyles is completely dependent for its carbohydrate and inorganic nutrient requirements on uptake from phloem sieve tubes in the host stem. The phloem is part of a plant's vascular system that transports organic compounds, especially sucrose, and minerals up and down the stem (Fig. 5.5). Pilostyles strands occur predominantly in the phloem (Dell et al., 1982). When reproductive tissues begin to form from the strands, Pilostyles starts to produce extensions ('pegs') into the host xylem. These pegs transfer extra water and minerals from the host xylem to the parasite. These extra nutrients are essential, as production of flower buds and flowers is a nutrientexpensive process.

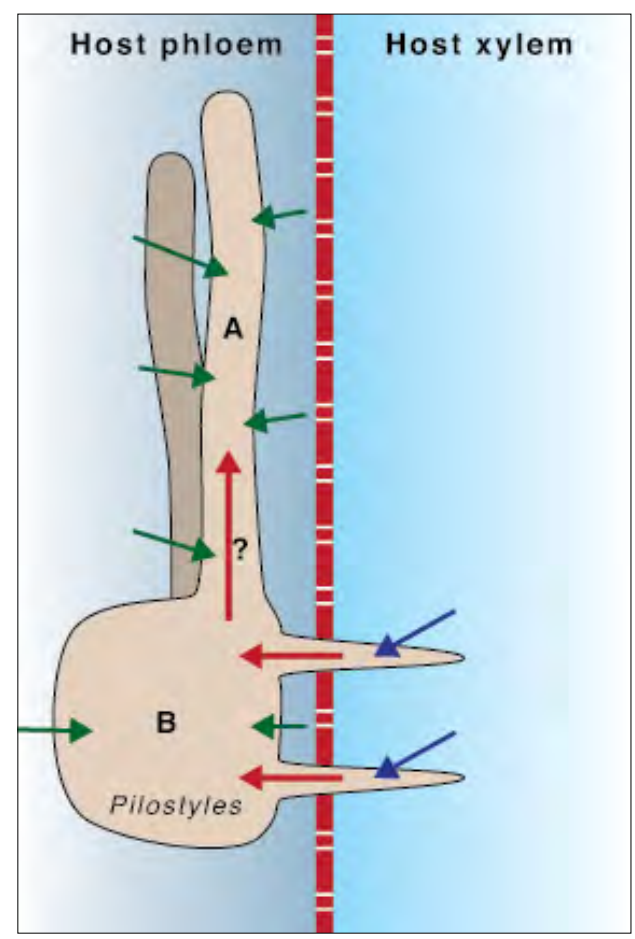

Fig. 5.5: Pathways of movement of host materials into Pilostyles. Vegetative tissue (A) utilizes primary phloem-derived nutrients, whereas reproductive tissues (B) utilize both phloem- (green arrows) and xylem-derived (blue arrows) nutrients. Red arrows represent internal parasite translocation of solutes. After Dell et al. (1982). 


\subsubsection{Cuscuta (Convolvulaceae)}

This inconspicuous holoparasite is an annual herb with thread-like yellow stems that twine around host stems. Leaves are scale-like and the plant loses its roots once it reaches a host. Favoured hosts are in the daisy family (Asteraceae) and Cuscuta may sometimes be seen parasitizing other annuals, such as Rhodanthe. The scores of tiny haustoria penetrate the host's parenchyma, xylem and phloem (Lamont, 1982b). Cuscuta campestris, an exotic cosmopolitan species recorded in the SouthWest, may severely reduce the growth and flowering of its host (Shen et al., 2005). Because of the non-green appearance of the plant and fact that it obtains carbohydrates from its host phloem it has usually been considered non-photosynthetic but chloroplasts have been detected. However, the activity of essential enzymes is neglible (Chudhury \& Sahu, 1999). Only one native Cuscuta occurs in the SouthWest, C. australis.

\subsection{Stem Hemi or Holoparasite? Cassytha (Lauraceae)}

Cassytha is a scrambling, leafless, vine-like plant that is a stem parasite adhering to hosts via many minute haustoria. Cassytha is free-living, obtaining all its inorganic nutrient requirements from its host, and is considered to be an obligate parasite (Shen et al., 2010). Cassytha species only tap host xylem, and provides its own source of carbon via photosynthesis. A seedling must attach itself to a host within a few weeks (McLuckie, 1924) otherwise it will perish. Once a host is parasitized the primary Cassytha stem dies back, losing contact with the soil.

A single Cassytha plant produces hundreds of haustoria, often on multiple hosts, and may also parasitize itself (autoparasitism) (Fig. 5.6). Cassytha is also known to display hyperparasitism, a situation where other parasitic species (e.g. Santalum, Nuytsia) are the hosts (Fig. 5.6). Cassytha haustoria are initiated before stem tissues are fully differentiated. A haustorium produces an adhesive disc that contains a thick layer of mostly unicellular, tightly packed microscopic hairs that fold at their tips upon contact with the host (Heide-Jorgensen, 1991). The hairs secrete adhesive mucilage that enables the haustorium to attach itself to the host. A wedge-shaped intrusive organ develops inside the layer of cells that lie immediately below the epidermis that penetrates the host stem via hydrostatic pressure and haustorial growth. Most of the starch that was stored in the adhesive disc before the intrusive phase is used during penetration (Fig. 5.6). The outer part of the storage tissue then forms a collapsed zone between the parasite and the host (Heide-Jorgensen, 1991). 

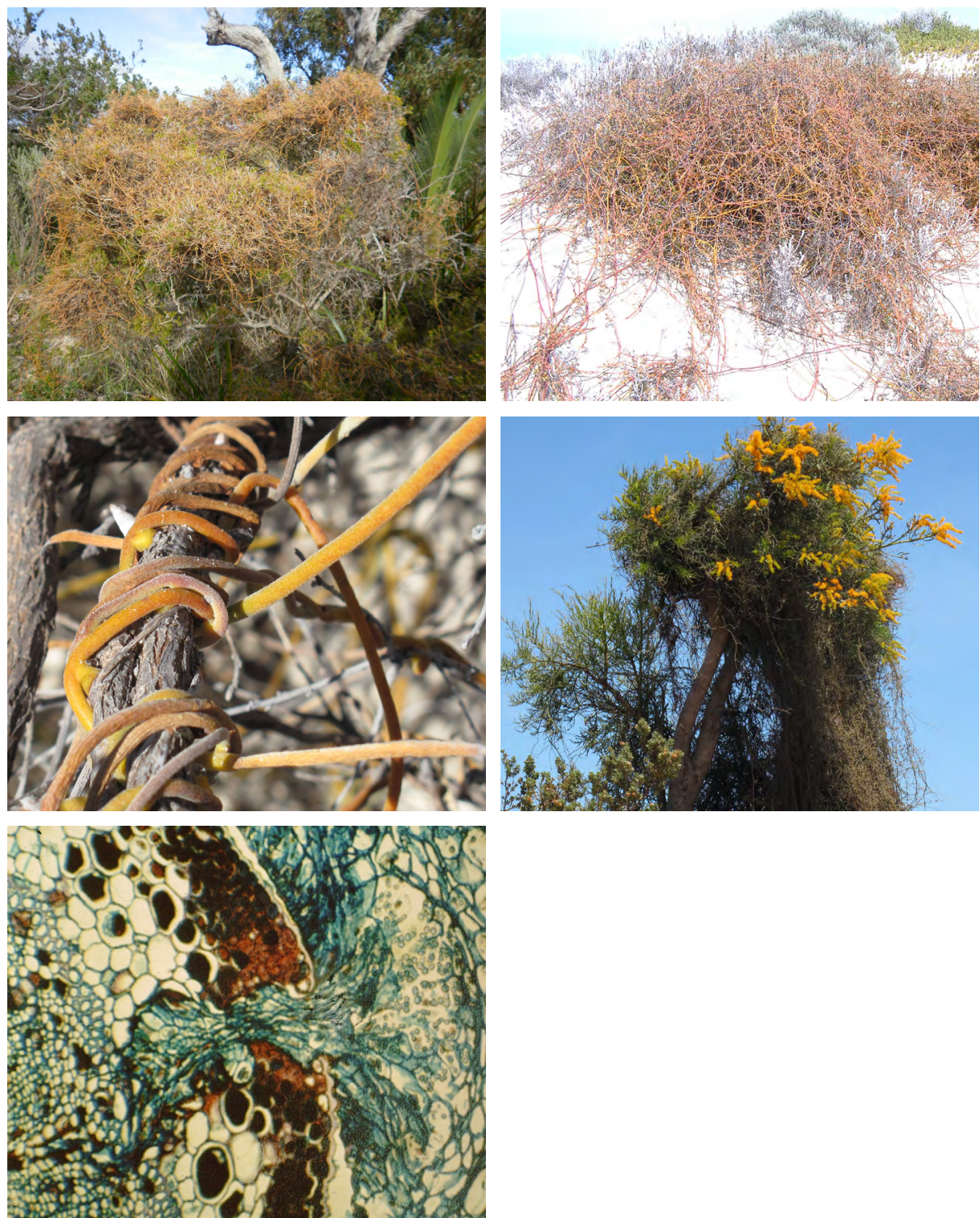

Fig. 5.6: (upper) Cassytha racemosa (1-3 m wide) smothering host plants in a banksia woodland (left) and on the coastal dunes (right) near Perth, Western Australia. (middle left) Cassytha haustorial connections to a host stem $8 \mathrm{~mm}$ in diameter. (middle right) Cassytha hyperparasitising the root parasite Nuytsia. (lower) Sucker of Cassytha haustorium (on right) penetrating young stem of Acacia saligna (on left) until it connects to the host's xylem. Note starch grains in the $0.5 \mathrm{~mm}$-wide core of the haustorium that serve to meet the energy requirements of the dynamic processes involved. 